\title{
A MÃo ESQUERDA DA ESCURIDÃo, DE URSULA K. LE GUIN, COMO EXPERIMENTO DE PENSAMENTO: UMA INVESTIGAÇÃO DO FAZER LITERÁRIO COMO FAZER FILOSÓFICO
}

\author{
Jade Bueno Arbo ${ }^{1}$ \\ Universidade Federal de Pelotas (UFPel) \\ https://orcid.org/0000-0001-5726-6545 \\ E-mail: jade.arbo@ufpel.edu.br \\ Bruna Schneid da Silva ${ }^{2}$ \\ Universidade do Estado do Rio de Janeiro (UERJ) \\ iD https://orcid.org/0000-0002-3361-4549 \\ E-mail: brunaschneid@outlook.com
}

\section{RESUMO:}

O presente trabalho se configura em um diálogo entre as áreas da literatura e da epistemologia para compreender o que significaria entender "A Mão Esquerda da Escuridão" (1969) como um experimento de pensamento. Ao aproximarmos a ficção científica enquanto gênero da noção de experimento de pensamento, concluímos que o deslocamento imaginativo realizado por autores de ficção científica, ao inventar pessoas, mundos, diferentes organizações políticas, e ao explorar, também, relações entre sujeitos dentro dessas estruturas e organizações sociais, elaboram experimentos de pensamento capazes de lidar com importantes aspectos da experiência humana.

PALAVRAS-CHAVE: Experimento de pensamento; Ursula K. Le Guin; Ficção científica; Metafilosofia.

\section{THE LEFT HAND OF DARKNESS, BY URSULA K. LE GUIN, AS THOUGHT EXPERIMENT: AN EXAMINATION OF LITERATURE AS PHILOSOPHY}

\begin{abstract}
:
This essay intersects literature and epistemology in order to understand what it means to take "The left hand of darkness" (1969), as proposed by the author Ursula K. Le Guin, as a thought experiment. As we look at Science Fiction as a literary genre and how it relates to the notion of thought experiment, we conclude that Science Fiction authors, through the imaginary displacement they perform as they create people, worlds, political organizations, and explore the relations between subjects within these imaginary structures, also draw thought experiments that are able to deal with important aspects of the human experience.
\end{abstract}

KEYWORDS: Thought experiment; Ursula K. Le Guin; Science Fiction; Metaphilosophy.

\footnotetext{
${ }^{1}$ Doutorando(a) em Literatura, Cultura e Tradução na Universidade Federal de Pelotas (UFPel), Pelotas - RS, Brasil..

${ }_{2}^{2}$ Doutorando(a) em Filosofias na Universidade do Estado do Rio de Janeiro (UERJ), Rio de Janeiro - RJ, Brasil. Bolsista do(a): Fundação Carlos Chagas Filho de Amparo à Pesquisa do Estado do Rio de Janeiro (FAPERJ), Rio de Janeiro - RJ, Brasil.
}

ARBO, Jade Bueno.; SILVA, Bruna Schneid da. A mão esquerda da escuridão, de Ursula k. Le Guin, como experimento de pensamento: uma investigação do fazer literário como fazer filosófico. Griot : Revista de Filosofia, Amargosa - BA, v.21 n.3, p.99111, outubro, 2021. 


\section{Introdução}

Ursula Le Guin, na introdução ao seu livro $A$ Mão Esquerda da Escuridão, nos diz que "a ficção científica não prevê; descreve" (LE GUIN, 2019 p. 12). Ao nos convidar a pensar na ficção científica não em termos de extrapolação preditiva, mas talvez de um experimento de pensamento $^{3}$, Le Guin nos guia a uma leitura de seu romance aberta às complexidades e inquietações que dizem respeito muito mais ao tempo presente do que ao tempo futuro. Para Le Guin:

Numa história concebida [como um experimento mental], a complexidade moral própria do romance moderno não precisa ser sacrificada, nem existe nela um beco sem saída inerente; o pensamento e a intuição podem mover-se livremente dentro dos limites estabelecidos pelas condições da experiência e que, na verdade, podem ser muito amplos (LE GUIN, 2019 p. 12).

A autora nos pede, já de início, cautela quanto à busca por respostas, e curiosidade com relação às perguntas que incita através de uma organização de "mentiras" - símbolos e metáforas - no papel.

Ao mencionar o fato de que, no romance que estamos prestes a ler, encontraremos personagens andróginos, Le Guin faz uma ressalva - certamente um adendo importante em um momento de feminismo de segunda onda ${ }^{4}$, durante o qual acirravam-se as disputas entre discursos de definição e afirmação do sujeito feminino -, a de que ela não está prevendo que seremos andróginos no futuro, e que não traz consigo uma proposta normativa de que devemos nos tornar andróginos.

Estou apenas observando, de maneira peculiar, tortuosa e experimental própria da ficção científica, que, se você olhar para nós em certos momentos, dependendo de como está o tempo lá fora, já somos andróginos. Não faço previsões, nem passo receitas. Descrevo. Descrevo certos aspectos da realidade psicológica à maneira do romancista, que é inventando mentiras elaboradas e circunstanciais (LE GUIN, 2019 p. 15).

Com isso, ao colocar sua escrita como descritiva e não como prescritiva, como um experimento de pensamento ao invés de uma predição, Le Guin não nos fornece uma chave de leitura para seu romance, mas condiciona nosso horizonte de expectativa, modifica nossa atitude para com ele.

Pensar a ficção científica como exercendo um papel filosófico parece bastante plausível quando lembramos que uma série de experimentos de pensamento filosóficos são explicitamente dignos de ficção científica, como no seguinte caso:

A maneira mais óbvia (embora não a única) de investigar a superveniência lógica da consciência é considerar a possibilidade lógica de um zumbi: alguém ou algo fisicamente idêntico a mim (ou a qualquer outro ser consciente), mas carente de experiências conscientes como um todo. Então, vamos considerar meu gêmeo zumbi. Esta criatura é molécula por molécula idêntica a mim, e idêntica em todas as propriedades de baixo nível postuladas por uma física completa, mas carece inteiramente de experiência consciente.

\footnotetext{
3 Optamos pelo uso da tradução "experimento de pensamento" em detrimento da também utilizada tradução "experimento mental" devido a carga teórica pressuposta no termo "mental".

${ }_{4}^{4}$ Para uma análise das tensões entre sujeitos do feminismo e das problemáticas da busca por uma teoria geral da opressão feminina durante a segunda onda, que dependia de uma noção forte de sujeito Mulher, ver Arbo, 2020.
} pensamento: uma investigação do fazer literário como fazer filosófico. Griot : Revista de Filosofia, Amargosa - BA, v.21 n.3, p.99111, outubro, 2021. 
(Alguns podem preferir chamar um zumbi "isso", mas eu uso o pronome pessoal; passei a gostar muito do meu gêmeo zumbi.) (CHALMERS, 1996, p. 95). ${ }^{5}$

Tal experimento de pensamento é desenvolvido por David Chalmers (1996) para justificar a possibilidade lógica da existência de seres humanos sem experiência consciente.

Tal qual os filósofos recorrem a experimentos de pensamento dignos de ficção científica para expressar as conviç̧ões dos indivíduos em situações que extrapolam o cenário cotidiano, cineastas e autores também lançam mão de mecanismos semelhantes. Assim, com todas as contingências do ser filósofo, nunca foi um requisito estar dentro dos contornos disciplinares da filosofia para produzir filosofia: Lana e Lilly Wachowski, por exemplo, ao trazerem o filme Matrix para as telas do cinema, trazem a discussão filosófica do ceticismo cartesiano ao explorar a existência de forma análoga ao experimento de pensamento do gênio maligno cartesiano. Ao fazêlo, também exploram as consequências desse ceticismo para concepções de agência e moralidade, trazendo questões próprias da filosofia para o campo das discussões no âmbito da cultura popular.

Noël Carroll (2020) realiza uma aproximação entre aspectos da ficção científica e da prática filosófica. Carroll define que:

As narrativas de ficção científica que nos preocupam tratam o mundo como se fosse um laboratório no qual os fatos sobre a estrutura do mundo - física e/ou tecnológica e/ou cultural e/ou histórica - podem ser imaginativamente variados a fim de contemplar o que é possível e/ou provável, muitas vezes junto com uma consideração do significado ético e/ou político previsto dessas alterações (CARROLL, 2020, p. 477-478) .

Uma ficção científica pode ser compreendida enquanto filosófica de diferentes modos; a obra em questão pode envolver um tema filosófico como The Eichmann Show (2015), um filme que convida seus espectadores a pensar a questão da dignidade humana, incentivando o filosofar enquanto discute com noções de certo e errado em nossa mente.

Uma ficção ainda pode apresentar uma perspectiva definida, nesse sentido ela nos oferece uma tese, por exemplo, quando em um cenário pós-apocalíptico e uma ordem deliberada por uma lei imperial prevalece em detrimento de outras formações de sociedade, como no exemplo do icônico Star Wars. Segundo Carroll:

Quer sejam temas ou teses, as ficções científicas podem juntar-se à filosofia ao nível da metafísica e/ou epistemologia, ou em questões de ética, teoria política e social, ou mesmo estética. Se Frankenstein contempla os limites do impulso humano para o conhecimento, Admirável Mundo Novo imagina o tipo de distopia que poderia surgir se uma sociedade fosse governada pelo princípio utilitário de maximizar o prazer do maior número (CARROLL, 2020, P. 481) ${ }^{7}$.

\footnotetext{
5 Tradução nossa. original: "The most obvious way (although not the only way) to investigate the logical superve-nience of consciousness is to consider the logical possibility of a zombie: someone or some-thing physically identical to me (or to any other conscious being), but lacking conscious experiences altogether. At the global level, we can consider the logical possibility of a zombieworld: a world physically identical to ours, but in which there are no conscious experiences at all. In such a world, everybody is a zombie. So let us consider my zombie twin. This creature is molecule-for-molecule identical tome, and indeed identical in all the low-level properties postulated by a completed physics, but he lacks conscious experience entirely. (Some might prefer to call a zombie "it", but I use the personal pronoun; I have grown quite fond of my zombie twin.)"

${ }^{6}$ Tradução nossa. No original: "The science fiction narratives that concern us treat the world as if it were a laboratory in which facts about the structure of the world - physical and/or technological and/or cultural and/or historical - can be imaginatively varied in order to contemplate what is possible and/or probable, often along with a consideration of the predicted ethical and/or political significance of these alterations."

7 Tradução nossa. No original: "Whether a matter of themes or theses, science fictions may join philosophy at the level of metaphysics and/or epistemology or in matters of ethics, political and social theory, or even aesthetics. If Frankenstein

ARBO, Jade Bueno.; SILVA, Bruna Schneid da. A mão esquerda da escuridão, de Ursula k. Le Guin, como experimento de pensamento: uma investigação do fazer literário como fazer filosófico. Griot : Revista de Filosofia, Amargosa - BA, v.21 n.3, p.99111, outubro, 2021.
} 
Assim, a atitude suscitada por Le Guin é, sem dúvidas, uma atitude filosófica de experimentação para a qual seu romance $A$ Mão Esquerda da Escuridão é terreno fértil. Mas com quais resultados? Examinaremos, então, o papel do experimento de pensamento para a filosofia para que possamos, dessa forma, verificar o fazer literário de Le Guin, nesse caso específico, e possivelmente da ficção científica e ficção especulativa enquanto gênero, como um fazer filosófico. Partiremos, para tanto, de uma compreensão desse método de investigação.

\section{0 experimento de pensamento na prática filosófica}

É certo dizer que toda investigação, seja em qual for a área do saber, envolve a contemplação de casos imaginários, seja na ciência com as descobertas de Isaac Newton acerca da velocidade de queda dos corpos, seja em livros didáticos de Direito que recorrem a casos hipotéticos para orientar a educação jurídica. Este método consiste em orientar o leitor a caminhos peculiares, inventados no "laboratório da mente", acerca de lugares e eventos que podem ou não ter existido, contando histórias de forma detalhada para que, ao fim da história, o leitor chegue a uma conclusão.

É a esse recurso de apelar a dispositivos da imaginação que damos o nome de experimento de pensamento. O termo, no original em alemão, Gedankenexperiment, foi cunhado por Hans Christian Ørsted e posteriormente desenvolvido enquanto experimento da imaginação por Ernst Mach (BROWN \& FEHIGE, 2019) ${ }^{8}$.

Brown e Fehige (2019) apresentam o desenvolvimento das investigações modernas acerca do experimento de pensamento em quatro fases. A primeira se dá entre os séculos XVIII e XIX, na qual emerge o interesse pelos experimentos de pensamento como ferramentas para a filosofia e para a ciência, e na qual podemos localizar Ørsted. A segunda ocorre no início do século XX de forma majoritariamente independente do primeiro estágio, e aqui podemos localizar Mach; um terceiro estágio, novamente tendo pouca relação com o anterior, se dá segunda metade do século $\mathrm{XX}$, "provavelmente devido à redescoberta da importância da prática científica para um bom entendimento da ciência" (BROWN \& FEHIGE, 2019, n.p.) ${ }^{9}$. Embora o terceiro estágio traga nomes importantes como Daniel Dennett e Karl Popper, Brown e Fehige (2019) consideram o quarto estágio, ainda em andamento e iniciado depois dos anos 1980, como o mais prolífico, no qual se discutem diferentes formas de conceber um experimento de pensamento com resultados variados $^{10}$.

Assim, independentemente da abordagem específica, filósofos comumente recorrem a casos imaginários para elaborar seus argumentos, e os experimentos de pensamento da ética podem ser tão bem descritos que nos direcionam a considerar intuitivamente a ação descrita como

\footnotetext{
contemplates limits to the human drive for knowledge, Brave New World imagines the kind of dystopia that might emerge if a society were run on the utilitarian principle of maximizing the pleasure of the greatest number."

${ }^{8}$ De acordo com Witt-Hansen (1976), Mach é comumente creditado como tendo cunhado o termo para seu emprego filosófico, no entanto Ørsted, químico e físico dinamarquês responsável pela identificação da primeira conexão entre eletricidade e magnetismo, já propunha uma ideia de experimento de pensamento, embora com um foco mais específico na observação de fenômenos naturais. 9 Tradução nossa. No original: "probably due to the rediscovery of the importance of scientific practice for a proper understanding of science".

10 Brown e Fehige (2019) trazem um exame detalhado das diferentes formas de se conceber um experimento de pensamento, nas quais estão inclusos o que chamam de "objeção cética", a "descrição baseada em intuição", a "visão do argumento", "construtivismo conceitual", "experimentalismo e a "descrição do modelo mental", nas quais não nos aprofundaremos aqui, mas cuja menção é importante para compreender a capilarização das discussões acerca dos experimentos de pensamento nesse prolífico quarto momento.
} pensamento: uma investigação do fazer literário como fazer filosófico. Griot : Revista de Filosofia, Amargosa - BA, v.21 n.3, p.99111, outubro, 2021. 
moralmente condenável ou moralmente permissível. Um bom exemplo de experimento de pensamento da ética é o proposto por Judith Jarvis Thomson, o famoso caso do Violinista, que versa sobre a questão da autonomia corporal:

Você acorda pela manhã e se encontra na cama deitado costa a costa com um violinista inconsciente. Um famoso violinista inconsciente. Ele foi diagnosticado com uma doença renal fatal, e a Society of Music Lovers analisou todos os registros médicos disponíveis e descobriu que apenas você tem o tipo de sangue certo para ajudar. Eles, portanto, sequestraram você e, ontem à noite, o sistema circulatório do violinista foi conectado ao seu, de modo que seus rins podem ser usados para extrair venenos de seu sangue. $O$ diretor do hospital agora lhe diz: "Olha, sentimos muito que a Society of Music Lovers tenha feito isso com você - nunca teríamos permitido se soubéssemos. Mas ainda assim eles fizeram isso e o violinista agora está conectado a você. Para desconectá-lo, seria necessário matálo. Mas não importa, é só por nove meses. Até lá ele se recuperará de sua doença e pode ser desconectado de você (THOMSON, 1971, p. 72) ${ }^{11}$.

Há ainda outros exemplos que podemos considerar paradigmáticos no método filosófico de recorrer a casos hipotéticos, alguns exemplos deste método são o anel de Gyges ${ }^{12}$, o experimento das Terras Gêmeas de Putnam ${ }^{13}$, a Máquina da Experiência de Nozick ${ }^{14}$, dentre outros.

Tamar Szabó Gendler (2000) sugere que, embora casos imaginários sejam indiscutivelmente diferentes de casos reais, as nossas respostas a casos imaginários podem ser tão relevantes quanto nossas respostas a casos reais, na condição de que possamos aplicar essas respostas, de alguma forma, em casos reais. No entanto, é preciso estar atento à complexa relação entre experimento de pensamento e realidade.

Uma distinção importante para pensar essa relação é a dada por Bealer (1998). Para o autor, os filósofos contemporâneos têm compreendido a noção de experimento de pensamento de forma equivocada, pois têm defendido que exemplos hipotéticos dão origem a intuições racionais ${ }^{15}$, no entanto, quando se trata de experimentos de pensamento, devemos ter em mente que estes originam intuições físicas ${ }^{16}$. Não será nossa preocupação analisar o controverso papel da

11 Tradução nossa.. No original: "You wake up in the morning and find yourself back to back in bed with an unconscious violinist. A famous unconscious violinist. He has been found to have a fatal kidney ailment, and the Society of Music Lovers has canvassed all the available medical records and found that you alone have the right blood type to help. They have therefore kidnapped you, and last night the violinist's circulatory system was plugged into yours, so that your kidneys can be used to extract poisons from his blood as well as your own. The director of the hospital now tells you, "Look, we're sorry the Society of Music Lovers did this to you - we would never have permitted it if we had known. But still, they did it, and the violinist now is plugged into you. To unplug you would be to kill him. But never mind, it's only for nine months. By then he will have recovered from his ailment, and can safely be unplugged for you."

${ }^{12}$ Experimento de pensamento platônico presente no Livro 2 de A República, que questiona a possibilidade de um sujeito agir de forma virtuosa caso não haja chances de ser detectado.

${ }_{13}$ Experimento de pensamento proposto por Hilary Putnam em seu artigo Meaning and Reference, publicado em 1973. Nele, Putnam propõe que imaginemos uma "Terra Gêmea" na qual a palavra "água" se refere não ao elemento H2O, e sim ao elemento XYZ. Esse cenário serve a Putnam como forma de defender que o significado dos termos depende da natureza do mundo em que determinados conceitos surgem.

${ }^{14}$ Também conhecida como "a máquina do prazer", constitui-se em um experimento de pensamento proposto por Robert Nozick em 1974, em seu livro chamado Anarchy, state, and utopia. Ao pedir que imaginemos uma máquina capaz de propiciar tudo o que desejamos e nos perguntar se preferimos viver nessa máquina ou na vida real, se contrapõe ao hedonismo ético que julga o prazer como o único valor intrínseco pelo qual diferenciar o que é bom do que é ruim.

15 Por intuições racionais, como definidas por Bealer (1998), compreende-se intuições que possuem uma relação de necessidade com a verdade. Pensemos aqui no famoso exemplo essencialista, é uma verdade necessária que "Água é igual a $\mathrm{H}^{2} \mathrm{O}$ ”.

${ }^{16}$ As intuições físicas não possuem uma relação necessária com a verdade, por exemplo, podemos pensar em um caso hipotético onde um copo está na beirada de uma mesa e tenho a intuição de que tal copo irá cair, todavia não é uma relação necessária que justifique a queda do copo, assim, podemos dizer que é provável que o copo irá cair.

ARBO, Jade Bueno.; SILVA, Bruna Schneid da. A mão esquerda da escuridão, de Ursula k. Le Guin, como experimento de pensamento: uma investigação do fazer literário como fazer filosófico. Griot : Revista de Filosofia, Amargosa - BA, v.21 n.3, p.99111, outubro, 2021. 
intuição ${ }^{17}$ na atividade filosófica, no entanto, cabe trazer a definição de Brendel (2020) segundo a qual as intuições são atitudes proposicionais imediatas e espontâneas, acompanhadas de um sentimento de certeza. Assim, ao tratarmos de intuições enquanto resultados de experimento de pensamento, estaremos falando de intuições naturalizadas ${ }^{18}$ que possuem certo papel de evidência na prática filosófica, como a intuição que nos faz crer que é moralmente justificável separar o violinista de nós, e, assim, moralmente justificando o aborto, ainda que o feto seja considerado uma pessoa ${ }^{19}$.

Assim, podemos categorizar um experimento de pensamento como hipotético ou contrafactual, em que hipotético designa uma situação que pode ocorrer de fato no mundo físico, enquanto um experimento contrafactual não tem relação direta com o mundo como ele é ou como ele pode ser de fato. Sua relação com a realidade parece ser mais abstrata e menos transparente do que experimentos hipotéticos.

O experimento de pensamento do violinista, por exemplo, é descrito por Thomson como uma metáfora para casos de aborto. Configura-se em um caso contrafactual no qual a filósofa coloca o leitor em uma situação que considera análoga ao aborto e extrai suas intuições do caso apresentado: mesmo que uma outra vida, seja ela qual for, dependa diretamente do meu corpo para a sua sobrevivência, isso não dá o direito irrevogável a essa vida de me manter presa ou confinada a ela, ou ao estado ou uma instituição de me manter presa a ela por um tempo determinado.

Para decifrar, então, esse experimento de pensamento, podemos nos utilizar da perspectiva de Gendler de que os experimentos de pensamento possuem uma estrutura que se constitui em três partes;

(1) Um cenário imaginário é descrito.

(2) Um argumento é oferecido que tenta estabelecer a correta avaliação do cenário.

(3) Esta avaliação do cenário imaginado é então levada para revelar algo sobre casos além do cenário (GENDLER, 2000, p. 21) ${ }^{20}$.

No experimento do Violinista, no cenário imaginário descrito (1), você descobre que foi sequestrado e que seu sistema circulatório foi conectado a um violinista inconsciente, seus rins são utilizados para extrair toxinas do sangue do violinista. A avaliação do cenário (2) é que as pessoas irão intuir que preferem ser desconectadas do violinista. $O$ cenário revela (3) que, mesmo quando consideramos o feto uma pessoa o aborto é considerado permissível.

\footnotetext{
${ }_{17}$ Uma série de filósofos analisam o papel que as intuições desempenham na atividade filosófica, se por um lado há filósofos que compreendem as intuições enquanto fontes confiáveis de evidência como Alvin Goldman (1998, 1999, 2007, 2010, 2011) e Janet Levin $(2004,2007,2009,2013)$, por outro lado há autores como Herman Cappelen (2012) e David Papineau (2013) que desafiam seus status probatório. Embora o termo seja recorrente na prática filosófica, seus oponentes alegam que os filósofos apelam as intuições sem empregar muitos critérios em seu uso.

${ }^{18}$ Nos utilizamos do termo "naturalizadas" para contrastar com noções racionalistas e platônicas de intuições. As intuições, nesse sentido, envolvem estamos mentais e conhecimento de fundo (background) que é resgatado quando essas intuições são ativadas (BRENDEL, 2004).

${ }^{19}$ Consideramos importante a observação de que o tema do aborto, tanto por um ponto de vista jurídico quanto por um ponto de vista moral, se configura em uma questão bastante complexa, a qual não acreditamos ser resolvida pelo experimento de pensamento proposto por Thompson. Assim, o experimento de Thompson se configura, conforme o trazemos aqui, em um exemplo da forma com a qual experimentos de pensamento se utilizam de intuições como forma de evidência para argumentar a favor ou contra certas ações - nesse caso, uma defesa do aborto.

${ }^{20}$ Tradução nossa. No original: "(1) An imaginary scenario is described. (2) An argument is offered that attempts to establish the correct evaluation of the scenario. (3) This evaluation of the imagined scenario is then taken to reveal something about cases beyond the scenario."
} pensamento: uma investigação do fazer literário como fazer filosófico. Griot : Revista de Filosofia, Amargosa - BA, v.21 n.3, p.99111, outubro, 2021. 
Gendler apresenta uma distinção entre três tipos de perguntas que podem ser feitas sobre experimentos de pensamento, sobretudo para responder às críticas de que as partes que integram um experimento de pensamento não garantem sua aplicabilidade no mundo real.

(1) O que aconteceria?

(2) Como, dado (1), devemos descrever o que aconteceria?

(3) Como, dado (2), devemos avaliar o que aconteceria? cenário (GENDLER, 2000, p. $25)^{21}$

O primeiro tipo de pergunta é chamado de "factivo", onde pensamos os fatos envolvidos na situação; o segundo é chamado de "conceitual", nesse sentido pensamos na aplicação adequada dos conceitos; o terceiro tipo é chamado de "valorativo", onde pensamos a relação moral ou estética adequadas.

As três questões que podem ser feitas aos experimentos de pensamento correspondem, então, aos tipos de experimento de pensamento. Os experimentos que correspondem à primeira questão são os experimentos de pensamento da ciência; os que correspondem à segunda questão são os experimentos da epistemologia e metafísica, e os que correspondem à terceira questão são da ética e estética.

Dessa forma, os três diferentes tipos de experimentos de pensamento nos direcionam a problemas filosóficos distintos. No primeiro, o problema levantado é considerar como pensar algo de maneira nova pode nos levar a adquirir novos conhecimentos sobre o mundo; podemos pensar aqui na relatividade do tempo, descrita pelo experimento de pensamento de Albert Einstein, por exemplo. No que se refere ao segundo e terceiro tipo, o problema levantado é acerca do que podemos aprender sobre nossos conceitos ou valores. De forma geral, pode-se dizer que esses experimentos pretendem descrever ou avaliar ações.

No caso de experimentos do primeiro tipo, podemos verificar os casos fazendo experimentos reais, em laboratórios reais. Por outro lado, no segundo e terceiro caso, exploramos conteúdos conceituais, fazendo experimentos no "laboratório da mente". O objetivo em ambos os casos é testar evidências, considerando hipóteses através de um método sistemático. Enquanto em um experimento da ciência fazemos modificações nas circunstâncias do mundo, nos casos hipotéticos e contrafactuais, os cenários são modificados.

Uma distinção que deve ser feita entre os casos científicos (1) e os casos conceituais (2) e avaliativos (3) é que nos casos (2) e (3) os filósofos já sabem o resultado que buscam atingir: sua preocupação é como descrevê-los ou avaliá-los. Assim, de que forma pensar essas categorias aplicadas ao gênero de ficção científica e às suas manifestações literárias, dada a sua igualmente complexa relação com a realidade? É o que veremos a seguir.

\section{A Mão Esquerda da Escuridão e a ficção científica como prática filosófica}

David Seed (2011), ao apontar a viagem para outros planetas como uma das primeiras imagens que nos vem à mente quando pensamos nesse gênero difuso e diverso que é a ficção científica, chama a atenção para o fato de que "a viagem espacial funciona como um mecanismo de estranhamento para com o mundo familiar, permitindo perspectivas externas (e geralmente

\footnotetext{
21 Tradução nossa. No original: “(1) What would happen? (2) How, given (1), should we describe what would happen? (3) How, given (2), should we evaluate what would happen?"
} 
irônicas), de serem construídas na Terra" (SEED, 2011)22. A ficção científica, portanto, se constitui em um gênero que retrata outros mundos como forma de possibilitar um olhar diferente sobre o nosso.

Com isso, retornamos à introdução de Le Guin a seu romance, em que coloca sua escrita como descritiva, e não como preditiva ou prescritiva. Dessa forma, ela nos prepara para buscar na história que estamos prestes a ler temas ao invés de teses.

Vemos que a relação que a autora estabelece com a realidade, com o que é derivável de e aplicável ao real, não é transparente, mas também não é indiferente ao real:

Escritores de ficção, pelo menos em seus momentos mais corajosos, realmente desejam a verdade: conhecê-la, dizê-la, servi-la. Mas seguem um caminho tortuoso e peculiar, que consiste em inventar pessoas, lugares e eventos que nunca existiram ou existirão de verdade, contando essas histórias fictícias de forma extensa, detalhada e com uma boa dose de emoção; e então, quando terminam de esquecer esse monte de mentiras, dizem “Aí está! Eis a verdade!" Escritores podem usar todo tipo de fatos para sustentar sua coleção de mentiras. [...] $\mathrm{O}$ peso de lugares, eventos, fenômenos e comportamentos verificáveis faz com que o leitor esqueça que o que está lendo é pura invenção, uma história que nunca ocorreu em lugar algum senão numa região ilocalizável: a mente do autor (LE GUIN, 2019, p. 13).

Para Le Guin, portanto, existe de fato nas obras de ficção mais corajosas um engajamento consciente com o real, um desejo pela verdade, por expressar, a partir do que chama de mentiras e metáforas, o real e o verdadeiro não em um sentido universal, mas de forma localizada: “(...) eles não dizem o que você vai ver e ouvir. Tudo o que podem dizer é o que viram e ouviram (...)" (LE GUIN, 2019, p. 13).

Dessa forma, para Le Guin, a ficção deriva de certos tipos de conhecimento, mas não um conhecimento universal, e sim um conhecimento localizado. Somos levados aqui a pensar na forma como Donna Haraway (1988) propõe a construção de conhecimento: para Haraway, a objetividade se constitui de diversas visões sobre os mesmos objetos, e precisamos ver de mais lugares para que possamos enxergar melhor e mais longe. A Mão Esquerda da Escuridão se constituiria, a partir disso, em uma adição localizada ao universo de discussões filosóficas, um ponto de vista.

De que forma podemos compreender, então, a adição que $A$ Mão Esquerda da Escuridão em específico faz à filosofia? De que forma as reflexões sobre a verdade, o real e a existência contidas no romance podem, para relembrar as palavras de Carroll (2013), juntar-se à filosofia e ajudar a informar reflexões filosóficas a nível de metafísica, epistemologia, ética, bem como em teoria política e social?

Vejamos a viagem à qual Le Guin nos conduz. A Mão Esquerda da Escuridão narra a história de Genly Ai, um emissário originário da Terra que é enviado ao planeta Gethen pela união de planetas e civilizações denominada Ekumen. Sua missão é convencer os habitantes de Gethen a se juntar ao Ekumen. Para auxiliá-lo, ele conta com diversos relatórios e observações de enviados que o precederam ao planeta, os quais surgem como capítulos em meio às narrativas em primeira pessoa de Genly e de Estraven, natural de Gethen, e informam, também, o leitor não apenas sobre a cultura e hábitos dos gethenianos, mas sobre a forma como esses hábitos são percebidos pelos povos do Ekumen.

${ }^{22}$ Tradução nossa. No original: "the space voyage functions as a device for estranging us from the familiar world, enabling external (and usually ironic) perspectives to be set up on Earth."

106

ARBO, Jade Bueno.; SILVA, Bruna Schneid da. A mão esquerda da escuridão, de Ursula k. Le Guin, como experimento de pensamento: uma investigação do fazer literário como fazer filosófico. Griot : Revista de Filosofia, Amargosa - BA, v.21 n.3, p.99111, outubro, 2021. 
O grande obstáculo de Genly é representado por sua dificuldade em lidar com os gethenianos, pois estes não são sexuados da mesma forma com a qual - em uma realidade mais próxima da autora do texto e da nossa - estamos acostumados.

Embora eu estivesse há quase dois anos em Inverno, estava ainda longe de conseguir ver as pessoas do planeta através de seus próprios olhos. Tentei, mas meus esforços tomaram a forma, desajeitada, de ver o quetheniano primeiro como homem, depois como mulher, forçando-o a uma dessas categorias tão irrelevantes à sua natureza, e tão essenciais à minha. Assim, enquanto bebericava minha cerveja amarga e fumegante, pensei que à mesa o desempenho de Estraven fora feminino, cheio de charme, tato e falta de substância, capcioso e astuto. Seria na verdade essa feminilidade suave e dócil que me fazia desgostar e desconfiar dele? Pois era impossível pensar nele como uma mulher, aquela presença escura, irônica, poderosa ali ao meu lado, na escuridão iluminada pelo fogo. Contudo, sempre pensava nele como homem, tinha a sensação de falsidade, de impostura: seria por causa dele ou de minha própria atitude em relação a ele? Sua voz era suave e ligeiramente ressonante, mas não forte; certamente não a voz de um homem, mas certamente tampouco a voz de uma mulher (...) (LE GUIN, 2019, p. 28-29).

Vemos que Genly Ai, aqui, não sabe interpretar os gethenianos, não sabe como vê-los, como tratá-los.

Esse é, assim, um dos experimentos de pensamento mais marcantes realizados por Le Guin em $A$ Mão Esquerda da Escuridão, que versa sobre a experiência generificada das sociedades ocidentais, e a dificuldade de repensarmos as fundações do que consideramos humano, dentre elas o gênero em coerência com um sexo biológico definido.

O capítulo intitulado $A$ questão do sexo é particularmente interessante, pois constitui-se de um relatório de um enviado anterior no qual ele examina e tenta dar sentido a uma ausência da constância do sexo biológico:

Considere: qualquer um pode trabalhar em qualquer coisa. (...) Considere: uma criança não tem nenhum relacionamento psicossexual com sua mãe ou seu pai. O mito de Édipo é inexistente em Inverno. Considere: não existe sexo sem consentimento, não existe estupro. [...] Considere: não existe nenhuma divisão da humanidade em metades forte e fraca, protetora/protegida, dominante/submissa, dona/escrava, ativa/passiva. Na verdade, pode-se verificar que toda a tendência ao dualismo que permeia o pensamento humano é muito reduzida, ou alterada, aqui em Inverno. (LE GUIN, 2019, p. 103)

Ao operar sua compreensão de sujeitos no mundo dentro de um binário masculino/feminino, o enviado partilha de nossas mesmas limitações de compreender um ser que exista fora desses termos.

Em suas diretrizes finais, o enviado recomenda de seus sucessores o impossível:

[...] quando encontrar um getheniano, não se pode e não se deve fazer o que um bissexual naturalmente faz, que é enquadrá-lo no papel de Homem ou de Mulher, enquanto adota, para com ele, o papel correspondente, dependendo de suas expectativas com respeito às interações padronizadas ou possíveis entre pessoas do mesmo sexo ou do sexo oposto. Todo o nosso padrão de interação sociossexual inexiste aqui. Eles não conseguem entrar no jogo. Não veem uns aos outros como homens ou mulheres. É quase impossível a nossa imaginação aceitar isso. Qual a primeira coisa que perguntamos sobre um recém-nascido? (LE GUIN, 2019, p. 103) pensamento: uma investigação do fazer literário como fazer filosófico. Griot : Revista de Filosofia, Amargosa - BA, v.21 n.3, p.99111, outubro, 2021. 
Como vimos nos trechos do romance trazidos até aqui, a ausência de um sexo biológico que garanta certa previsibilidade às performances dos indivíduos como sendo ou masculinas, ou femininas, desestabiliza a compreensão desses sujeitos como humanos, bem como a compreensão de suas práticas sexuais dentro de um espectro de hétero/homossexualidade.

É significativo que, em 1969, Le Guin já evidenciasse através de suas mentiras e metáforas o que a filósofa Judith Butler chamou, em 1990, de matriz de inteligibilidade do gênero. Butler descreve a forma como o gênero é parte do que humaniza os sujeitos, e essa manutenção da ficção do gênero como identidade fixa (o sujeito sendo, substancialmente, ou masculino, ou feminino) depende de uma igual manutenção da coerência entre sexo biológico, gênero, desejo e práticas sexuais (BUTLER, 2016). Dessa maneira, quando o relatório do emissário nos questiona "Qual a primeira coisa que perguntamos sobre um recém-nascido?", Le Guin está investigando, trazendo à nossa atenção, o que Butler (1997) quase trinta anos depois apontaria como o ato de fala fundante do sujeito enquanto pessoa: o estatuto de pessoa é fundado juntamente e a partir de seu estatuto generificado. Sem esse ato fundante, o que temos?

Utilizando-nos da classificação de Gendler (2000), a qual trouxemos na seção anterior, temos (1) um cenário imaginário descrito, mas não estão claros (2) os argumentos oferecidos para o estabelecimento de uma correta avaliação deste cenário apresentado, embora ainda sim esteja claro (3) que esse cenário verse sobre casos além do cenário apresentado por Le Guin.

Faz sentido que o segundo critério de Gendler não seja bem atendido nesse contexto, já que o texto literário é caracterizado por uma grande abertura a leituras diversas, e a recortes variados dos temas que possibilita (EAGLETON, 2019). Da mesma forma, o caráter descritivo assumido por Le Guin não permitiria chegarmos a um argumento estabelecido de avaliação desse cenário. Assim, como chegar ao terceiro elemento proposto por Gendler sem atender ao segundo?

Aqui, o conceito de "deslocamento imaginativo" proposto por Aaron Passell se torna interessante para pensarmos esse experimento de pensamento trazido por Le Guin em seu romance. Passell propõe a ficção científica e especulativa como um experimento de pensamento sociológico, que formaria uma fundação de um processo intelectual de descobrir e interrogar o status quo, destacando "como as coisas são ao imaginar como as coisas poderiam ser diferentes. Como explica Passell:

Sociólogos podem descrever esse tipo de questão em termos de fenômenos sociais particulares variáveis enquanto mantendo outros constantes: se nós imaginarmos que os humanos nesse universo alternativo são semelhantes às pessoas que conhecemos e em meio das quais vivemos, mas, por exemplo, têm acesso a tecnologia que permite a eles fazer algo que não podemos, como colonizar Marte, como eles fariam isso? $O$ que aconteceria e o que resultaria? (...) Ao mudar alguns aspectos da vida social, então, enquanto mantendo outros constantes, romances de ficção científica nos permitem executar experimentos mais como aqueles que nossos colegas nas ciências naturais fazem. Podemos hipotetizar uma relação, podemos criar modelos para testá-la (métodos trabalhados de forma complexa no decorrer da narrativa), e podemos examinar nossos resultados, considerando se eles confirmam, contradizem ou modulam nossa concepção original (PASSELL, 2013, p. 60) ${ }^{23}$.

\footnotetext{
23 Tradução nossa. No original: "Sociologists might describe this kind of question in terms of varying particular social phenomena while holding others constant: if we imagine that the humans in this alternate setting are roughly like the people we know and live among, but, for example, have access to technology that allows them to do something we can't, like settle on Mars, how would they go about doing so? What would happen and what would result? (...) In varying some aspects of social life, then, while holding others constant, SF novels enable us to perform experiments more like those that our colleagues in the natural sciences do. We can hypothesize a relationship, we can create a model to test it (methods intricately worked out in the course of the narrative), and we can examine our results, considering whether they confirm, dispute, or inflect our original conception".
} 
Nesse sentido, ao considerarmos que autores de ficção científica articulam questões próprias da sociologia, podemos pensar, então, que esses experimentos de pensamento os quais acreditamos estar presentes nesse gênero, ao inventar pessoas, mundos, diferentes organizações políticas, e ao explorar, também, relações entre sujeitos dentro dessas estruturas e organizações sociais, trazem importantes aspectos da experiência humana para o centro de uma investigação inerentemente filosófica. $O$ segundo critério de Gendler seria, assim, preenchido não por uma avaliação moral, mas por uma articulação descritiva de como pessoas, sociedades, organizações e instituições agiriam dado o cenário descrito.

O deslocamento realizado por Le Guin, e também apontado por Passell, é que os gethenianos não possuem um sexo biológico definido. Eles assumem um sexo - macho ou fêmea apenas periódica e temporariamente, e o sexo que assumirão durante seu período fértil não é previsível a eles, e é apenas conhecido no momento de contato com outra pessoa que também esteja no seu período fértil. Fora desse período, os gethenianos não são sexualmente ativos ou capazes de performar atos sexuais. Assim, na maior parte do tempo, as pessoas não são nem homens, nem mulheres, nem machos e nem fêmeas, e podem ser tanto pais quanto mães em diferentes momentos de suas vidas.

Passell elabora o deslocamento imaginativo de Le Guin da seguinte forma: "essa fisiologia curiosa é o pano de fundo bio-sexual de uma história sobre intriga política envolvendo nações rivais em competição para forjar a primeira aliança com o império que o emissário representa" (PASSELL, 2013, p. 62) ${ }^{24}$, e como pano de fundo, esse arranjo bio-sexual alienígena, ao condicionar a visão de Genly Ai sobre seus habitantes, permeia sua percepção não só da humanidade desses sujeitos, mas suas descrições da sociedade getheniana como um todo.

\section{Considerações finais}

As intuições levantadas na exploração da questão de gênero por Le Guin em $A$ Mão Esquerda da Escuridão, ao trazer preocupações sociológicas para um exercício filosófico, se comprometem muito mais em explicitar as formas com as quais nossas relações são pautadas em estereótipos de relações de gênero do que prover um julgamento moral normativo positivo - o que se deve fazer - sobre a situação descrita. No máximo, é possível derivar uma avaliação negativa de Genly e sua adesão acrítica - e também sua dependência - da matriz de inteligibilidade do gênero.

A partir dessa avaliação fraca em termos normativos, é possível dizer que o experimento de pensamento elaborado no "laboratório da mente" de Le Guin, ao nos confrontar com os esforços frustrados de Genly Ai em ver os gethenianos através de seus próprios olhos, apenas para vê-los primeiro como homens e então como mulheres, "forçando-o a uma dessas categorias tão irrelevantes à sua natureza, e tão essenciais à minha", nos mostra, como em um espelho, nossas próprias incapacidades de pensar os sujeitos fora desses termos. E a partir dessa avaliação, Le Guin versa sobre uma sociedade que sofre - e que deve superar - a incapacidade de pensar sujeitos outros, que vivem sob termos outros, nos chamando a questionar nossas concepções do que é essencial e universal ao humano.

24 Tradução nossa. No original: "This curious physiology is the bio-sexual background of a story of political intrigue involving rival nations in competition to forge the first alliance with the empire the emissary represents." 
Assim, esperamos ter demonstrado no decorrer deste trabalho, guiados pela afirmação de Le Guin sobre o caráter de experimentação de seu livro A Mão Esquerda da Escuridão, que, diferentemente de constituírem um experimento científico com equivalência transparente com a realidade, os experimentos de pensamento literários levantam problemas sobre o que podemos aprender sobre nossos conceitos e valores. Dessa forma, uma abordagem da literatura de ficção científica nos termos de experimentos de pensamento filosóficos nos fornecem um caminho para a análise dos temas e sintomas trazidos por essa literatura, dos questionamentos e deslocamentos, e de suas proposições e análises do presente.

ARBO, Jade Bueno.; SILVA, Bruna Schneid da. A mão esquerda da escuridão, de Ursula k. Le Guin, como experimento de pensamento: uma investigação do fazer literário como fazer filosófico. Griot : Revista de Filosofia, Amargosa - BA, v.21 n.3, p.99111, outubro, 2021. 


\section{Referências}

ARBO, J. O Feminismo em outros termos: da crítica ao sujeito fundacional feminista à ética da precariedade em Judith Butler. Orientadora: Flávia Carvalho Chagas, 2020. Dissertação (Mestrado em Filosofia) - Instituto de Filosofia, Sociologia e Política, Universidade Federal de Pelotas, Pelotas, 2020.

BEALER, G. Intuition and the autonomy of Philosophy. In DEPAUL, M. RAMSEY, W. Rethinking Intuition: The Psychology of Intuition and Its Role in Philosophical Inquiry. United States of America: Rowman \& Littlefield Publishers, Inc, 1998.

BRENDEL, E. Intuition Pumps and the Proper Use of Thought Experiments. Dialectica, v. 58, $n$ 1, p. 89 - 108, 2004. Disponível em https://www.jstor.org/stable/42970833?seq=1 acesso em 16 de novembro de 2020 .

BROWN, J. R.; FEHIGE, Y. Thought Experiments, In: ZALTA, E. N. The Stanford Encyclopedia of Philosophy, 2019. Disponível em: https://plato.stanford.edu/entries/thoughtexperiment/ acesso em 10 de outubro de 2020.

BUTLER, J. Excitable Speech: the politics in the performative. Routledge, 1997.

BUTLER, J. Problemas de gênero: feminismo e subversão da identidade. Rio de Janeiro: Civilização Brasileira, 2016. Trad. Renato Aguiar.

CARROL, N. Science fiction, Philosophy and Politics: Planet of the Apes as a Thought Experiment. Ethical Perspectives, v. 20, n. 3, p. 477-493, 2013. Disponível em https://poj.peeters-leuven.be/content.php?id=2992659\&url=article.php acesso 10 de novembro de 2020.

CHALMERS, D. The conscious mind: in search of a fundamental theory. Oxford University Press, 1996.

EAGLETON, T. Teoria da literatura: uma introdução. São Paulo: Martins Fontes, 2019.

GENDLER, T. S. Thought Experiment: On the powers and limits of imaginary cases. Garland Publishing, 2000.

LE GUIN, U. A mão esquerda da escuridão. Aleph, 2019. Trad. Susana L. de Alexandria

HARAWAY, D. Situated knowledges: the science question in feminism and the privilege of a partial perspective. Feminist Studies 14 no. 3 . Fall, 1988. Disponível em https://www.jstor.org/stable/3178066? seq=1 acesso 5 de outubro de 2020.

PASSELL, A. SF Novels and Sociological Experimentation: Examining Real World Dynamics through Imaginative Displacement, In: THOMAS, P. L. (Ed.) Science Fiction and Speculative Fiction: Challenging Genres. Sense Publishers, 2013.

SEED, D. Science fiction: a very short introduction. Oxford University Press, 2011.

THOMSON, J. A defense of abortion. Philosophy \& Public Affairs, v. 1, n. 1, p. 69-80, 1971. Disponível em http://www.jstor.org/stable/2265091 acesso 16 de outubro de 2020.

WITT-HANSEN, J., H.C. Ørsted, Immanuel Kant and the Thought Experiment, Danish Yearbook of Philosophy, Vol.13, (1976), pp. 48-65.

Contribuição dos(as) autores(as) / Author's Contributions: Jade Bueno Arbo foi responsável pela concepção do tema e do objeto de análise, subsidiando os diálogos específicos referentes a gênero, Ficção Científica e literatura. Bruna Schneid da Silva desenvolveu paralelos com o papel do experimento de pensamento na filosofia e a análise dos exemplos trazidos. Ambos aceitaram e aprovaram a versão final do texto.

Autor(a) para correspondência / Corresponding author: Jade Bueno Arbo. jade.arbo@ufpel.edu.br 